\title{
Membrane Action of Cladding Subjected to Blast Loading and Effects on the Supporting Structure
}

\author{
Orestis Ioannou * and Charis J. Gantes ${ }^{(D)}$ \\ Institute of Steel Structures, School of Civil Engineering, National Technical University of Athens, \\ 9 Heroon Polytechniou Street, GR 15780 Zografou, Greece; chgantes@central.ntua.gr \\ * Correspondence: iorestis@central.ntua.gr
}

Citation: Ioannou, O.; Gantes, C.J.

Membrane Action of Cladding Subjected to Blast Loading and Effects on the Supporting Structure. Vibration 2021, 4, 768-786. https://doi.org/ 10.3390/vibration4040043

Academic Editor: Damian Beben

Received: 8 September 2021

Accepted: 2 October 2021

Published: 6 October 2021

Publisher's Note: MDPI stays neutral with regard to jurisdictional claims in published maps and institutional affiliations.

Copyright: (c) 2021 by the authors. Licensee MDPI, Basel, Switzerland. This article is an open access article distributed under the terms and conditions of the Creative Commons Attribution (CC BY) license (https:/ / creativecommons.org/licenses/by/ $4.0 /)$.

\begin{abstract}
A recent blast design trend is to properly select cladding characteristics in order to limit blast consequences on its supporting structure. In this context, it is worth noting that cladding components may exhibit significant membrane action, and its effects may be decisive for the supporting structure. The main focus of the present study was to examine these effects through two-step dimensionless SDOF analyses, aimed at reaching conclusions that would be applicable to a large variety of cladding/supporting structure arrangements. The results of these analyses are presented by employing the dynamic load factor, representing the maximum supporting structure displacement. It was found that cladding membrane action has adverse effects over its supporting structure, as it does not allow for extensive plastic dissipation and leads to higher support reactions. On the contrary, insignificant membrane action leads to lower dynamic load factor for the supporting structure. Thus, membrane behavior should be activated only as a safety backup action in order to prevent cladding failure. A case study of a typical cladding/supporting structure is presented to demonstrate and verify the proposed two-step SDOF analyses and the obtained results.
\end{abstract}

Keywords: blast loading; cladding; supporting structure; membrane action; dynamic load factor; blast mitigation

\section{Introduction}

Building cladding constitutes the first structural component upon which blast pressure is applied during an external explosion incident. Hence, cladding should be designed accordingly, aiming at preventing the blast wave from entering the building and averting hazardous consequences in the building interior. If cladding is sufficiently strong, the main structure also needs to resist the explosion effects, as it offers support to the cladding. Thus, the main structure should also be designed against blast loading and, more specifically, against the dynamic reactions transmitted to it from the cladding.

However, while cladding is usually designed against blast loading assuming plastic energy dissipation, it may be desirable to design the main structure elastically. The main structure is generally considered as non-sacrificial [1,2], and the integrity of the main columns, at least, should be sustained, ensuring that they exhibit minimal lateral displacements with limited P- $\Delta$ effects [3]. Hence, the blast-induced dynamic forces transmitted to the supporting structure by the cladding should be reduced to the highest extent. Such dynamic actions on the supporting structure may be altered by properly modifying the cladding characteristics, i.e., its resistance, stiffness, and mass.

In this context, the cladding membrane behavior has been found to be critical, as it leads to increased in-plane and out-of-plane reaction forces [4,5]. Generally, the cladding is designed assuming inelastic flexural action against blast effects, but it may also be designed with catenary action [6]. However, in order for membrane resistance (catenary action) to be efficiently used, large deformations are needed, and the respective connections should be designed accordingly, exhibiting appropriate strength and ductility. These structural 
implications, associated with membrane action, have limited the exploitation of membrane action in typical structural engineering practice. On the other hand, the opposite is the case in blast-resistant design, as catenary action is extensively applied to safeguard structures against progressive collapse through slabs and tie beams [7], to protect laminated glass panes with PVB layers [8], or to serve as a reserve safety for structural components that have exhausted their bending strength and ductility [6].

The effects of panel stiffness on its maximum reaction forces have been analytically examined in [9] for the case of a clamped rectangular plate. It was found that in the elastic limit of both the quasi-static and the impulsive regime, the transmitted membrane forces were significantly increased with thickness decrease. Sandwich panels consisting of a face plate, a core, and a back plate have also been found to lead to increased reaction stretching forces when subjected to blast loading [4]. When compared with equivalent thickness solid plates with significant membrane behavior, it was shown that the sandwich panels lead to lower out-of-plane reaction forces [5].

The membrane resistance is even more significant for glass panes due to their small thickness. As noted in [10], membrane forces are increased when laminated glass is deformed. This happens up to the post-crack phase, where only membrane resistance is activated, and the respective reaction forces (both in-plane and out-of-plane) are so large that they should be calculated in detail for the glass fixings design.

In the present research study, the influence of cladding membrane behavior on the supporting structure was examined through dimensionless SDOF (Single Degree of Freedom) models. The dimensionless SDOF models were employed because they can lead to generalized observations about a variety of cladding material and geometric arrangements that can be described by the respective material model. Dimensionless diagrams are produced offering quantitative and qualitative estimations about the role of cladding membrane behavior over the supporting structure. The observations are demonstrated and verified through a numerical model of a typical steel cladding-to-supporting structure application.

\section{Dimensionless SDOF Analysis of the Cladding to the Supporting Structure System}

\subsection{Derivation of Equations of Motion}

The modeling of the cladding-to-supporting structure system was accomplished through a two-step SDOF time history analysis, as shown in Figure 1.

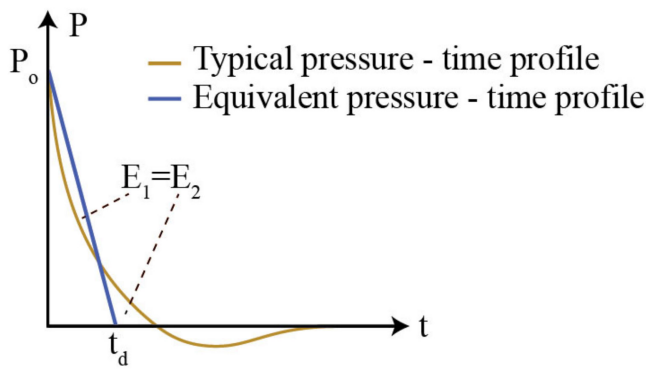

(a)

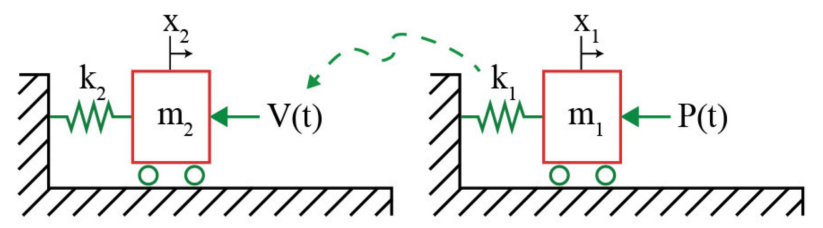

Supporting structure

Cladding

(b)

Figure 1. (a) Pressure time profile for blast loading and (b) two step SDOF analysis.

First, an SDOF analysis was performed representing the cladding subjected to blast loading (first step). Subsequently, another SDOF analysis was performed representing the 
supporting structure subjected to the dynamic reactions of the cladding (second step). The corresponding displacements are denoted by $x_{1}$ (cladding) and $x_{2}$ (supporting structure).

The spring that is associated with cladding stiffness is described by the force-displacement diagram of Figure 2. Generally, the membrane effects can be incorporated through various methodologies. An analytical methodology for predicting the maximum displacement of a structural component subjected to blast loading by taking into account the membrane effects of the cladding has been presented in [11]. Along with this methodology, extended SDOF approaches with membrane properties have also been presented in $[12,13]$. In the present study, the approach that is prescribed in [13] was adopted. According to this approach, an initial elastic stiffness $k_{1,1}$ is assigned to the SDOF. When the cladding reaches its ultimate resistance $R_{u}$, its stiffness is set to zero $\left(k_{1,2}=0\right)$, until the cladding develops sufficiently large displacements $\left(x_{1, \text { mem }}\right)$ to initiate membrane action.

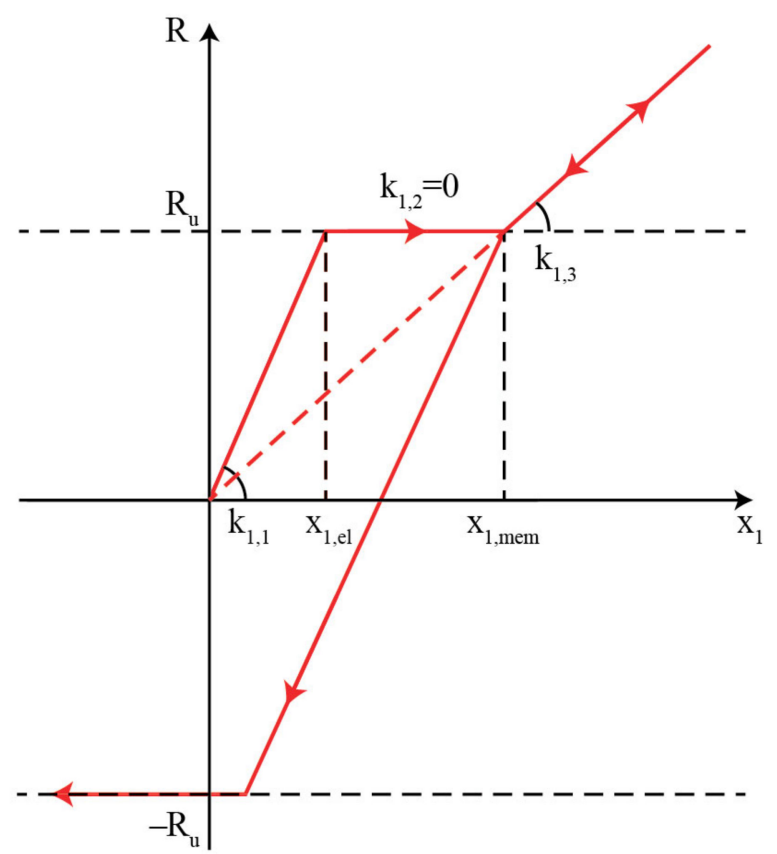

Figure 2. Force-displacement diagram of cladding with both bending and membrane stiffness.

If the membrane stiffness $k_{1,3}$ is lower than the bending stiffness $k_{1,1}$, the cladding exhibits both bending and membrane behavior. However, if the membrane stiffness $k_{1,3}$ is significantly higher than the bending stiffness $k_{1,1}$, the cladding can be considered to be a purely tensile structure, depending only on $k_{1,3}$ and neglecting both $k_{1,1}$ and the horizontal plasticity branch in the force-displacement diagram. This difference is discussed further in Section 3 (both bending and membrane stiffness) and Section 4 (membrane structure).

The unloading curve of the force-displacement diagram was applied as suggested in [14]. More specifically, the unloading curve corresponds to linear material and nonlinear geometry. Thus, the horizontal branch of the loading curve, which accounts for the effects of plasticity, is neglected in the unloading phase. Plasticity is then reactivated during rebound if the force reaches the cladding negative ultimate resistance, $-R_{u}$.

The cladding and supporting structure masses are denoted by $m_{1}$ and $m_{2}$, respectively. Along with mass $m_{1}$, the load-mass transformation factor is employed in order to appropriately convert the cladding component into an SDOF, where $\mathrm{a}_{1,1}, \mathrm{~b}_{1,1}, \mathrm{a}_{1,2}$, and $b_{1,2}$ constitute the respective coefficients for the cladding dynamic reactions [15]. Furthermore, the supporting structure spring is considered as elastic (due to its non-sacrificial characteristics explained in Section 1) and is denoted by $k_{2}$.

The corresponding equations of motion and dynamic reactions $V(t)$ of the cladding SDOF are described by Equations (1)-(7), separated into the various regions of cladding response, i.e., the elastic region, the plastic region, and the membrane action region. The 
equations are also applicable during the unloading of the cladding SDOF in a similar manner as for the aforementioned regions. In these equations, the blast loading $P(t)$ is applied as an equivalent triangular load, as discussed in [16] and shown in Figure 1, while the cladding membrane stiffness is calculated by employing the cladding axial resistance $N_{p}$ and length $L$. Moreover, damping has not been accounted for because it has negligible effects in blast-resistant design $[17,18]$. The support reaction $V(t)$ is doubled when applied to the supporting structure because it refers to the reactions of both adjacent cladding components.

$$
\begin{gathered}
m_{1} \cdot \ddot{x}_{1}+k_{1,1} \cdot x_{1}=P(t), x_{1}<x_{1, e l} \\
V(t)=a_{1,1} \cdot R(t)+b_{1,1} \cdot P(t), x_{1}<x_{1, e l} \\
m_{1} \cdot \ddot{x}_{1}+R_{u}=P(t), x_{1, e l} \leq x_{1}<x_{1, \mathrm{mem}} \\
V(t)=a_{1,2} \cdot R_{u}+b_{1,2} \cdot P(t), x_{1, e l} \leq x_{1}<x_{1, \mathrm{mem}} \\
m_{1} \cdot \ddot{x}_{1}+k_{1,3} \cdot x_{1}=P(t), x_{1} \geq x_{1, \mathrm{mem}} \\
V(t)=\left(2 \cdot N_{p} / L\right) \cdot x_{1}, x_{1} \geq x_{1, \mathrm{mem}} \\
m_{2} \cdot \ddot{x_{2}}+k_{2} \cdot x_{2}=2 \cdot V(t)
\end{gathered}
$$

The equations of motion can be further developed in non-dimensional form through the parameters of Equations (8)-(11). The non-dimensionalization of the displacement is performed by dividing with the static displacement $x_{s t 2}=P_{o} / k_{2}$, while the non-dimensionalization of time is performed by dividing with the blast positive phase duration $t_{d}$ and natural period of the supporting structure $T_{2}$.

$$
\begin{gathered}
n_{1}=\frac{x_{1}}{\left(\frac{P_{o}}{k_{2}}\right)} \\
n_{2}=\frac{x_{2}}{\left(\frac{P_{o}}{k_{2}}\right)} \\
P(t)=P_{o} \cdot\left(1-\frac{t}{t_{d}}\right) \\
\xi=\frac{t}{T_{2}}=\frac{t}{\left(2 \pi \sqrt{m_{2} / k_{2}}\right)}
\end{gathered}
$$

By applying a similar procedure with the one described in [15], Equations (1)-(7) can be converted into Equations (12)-(18). According to these equations, the maximum displacement of the supporting structure can be estimated through the maximum value of $n_{2}$, which constitutes the $D L F_{2}$ (Dynamic Load factor, ratio of maximum displacement $x_{\max 2}$ to static displacement $x_{s t 2}$ ) of the supporting structure.

$$
\begin{gathered}
\frac{m_{1}}{m_{2}} \cdot \frac{1}{4 \pi^{2}} \cdot \ddot{n_{1}}+\frac{k_{1,1}}{k_{2}} \cdot n_{1}=1-\xi \cdot \frac{T_{2}}{t_{d}, n_{1}<n_{1, e l}} \\
\frac{V\left(\xi \cdot T_{2}\right)}{P_{o}}=a_{1,1} \cdot \frac{k_{1,1}}{k_{2}} \cdot n_{1}+b_{1,1} \cdot\left(1-\xi \cdot \frac{T_{2}}{t_{d}}\right), n_{1}<n_{1, e l} \\
\frac{m_{1}}{m_{2}} \cdot \frac{1}{4 \pi^{2}} \cdot \ddot{n_{1}}+\frac{R_{u}}{P_{o}}=1-\xi \cdot \frac{T_{2}}{t_{d}, n_{1, e l} \leq n_{1}<n_{1, m e m}} \\
\frac{V\left(\xi \cdot T_{2}\right)}{P_{o}}=a_{1,2} \cdot \frac{R_{u}}{P_{o}}+b_{1,2} \cdot\left(1-\xi \cdot \frac{T_{2}}{t_{d}}\right), n_{1, e l} \leq n_{1}<n_{1, m e m} \\
\frac{m_{1}}{m_{2}} \cdot \frac{1}{4 \pi^{2}} \cdot \ddot{n_{1}}+\frac{k_{1,3}}{k_{1,1}} \cdot \frac{k_{1,1}}{k_{2}} \cdot n_{1}=1-\xi \cdot \frac{T_{2}}{t_{d}, n_{1} \geq n_{1, m e m}} \\
\frac{V\left(\xi \cdot T_{2}\right)}{P_{o}}=\frac{k_{1,3}}{k_{1,1}} \cdot \frac{k_{1,1}}{k_{2}} \cdot \frac{1}{2} \cdot n_{1}, n_{1} \geq n_{1, m e m}
\end{gathered}
$$




$$
\frac{1}{4 \pi^{2}} \cdot \ddot{n_{2}}+n_{2}=\frac{V\left(\xi \cdot T_{2}\right)}{P_{o}}
$$

The above differential equations were solved in MATLAB [19] for a wide range of the five dimensionless parameters $m_{2} / m_{1}, k_{2} / k_{1,1}, R_{u} / P_{o}, k_{1,3} / k_{1,1}$, and $t_{d} / T_{2}$. The Newmark average acceleration method was applied with $\gamma=0.5, \beta=0.25$, and a sufficiently small time step in order to capture the maximum displacement at the first oscillation cycle, as noted in [20].

\subsection{Assumptions and Limitations}

The range of validity of the described two-step SDOF analysis is restricted by several limitations, which are summarized as follows:

- The actual cladding-to-supporting structure system is more complicated with regard to the distribution of mass and stiffness than the employed lumped mass SDOF models. The respective transformation factors are considered uniform throughout the analyses.

- For the sake of simplicity, the dynamic reactions $V(t)$ correspond to simply supported components with uniformly distributed load and uniformly distributed mass $\left(a_{1,1}=0.39, b_{1,1}=0.11, a_{1,2}=0.38, b_{1,2}=0.12\right.$ [21] $)$. It is noted that the respective values of the dynamic reactions in fixed components are approximately equal with the ones in the simply supported components.

- Plasticity can only be captured by the horizontal branch of the force-displacement diagram, while in actual cases the cladding's response may be composed of multilinear regions with smooth transitions.

- Membrane action, which is considered through stiffness $k_{1,3}$, is only an approximation of the physical system's response, where the membrane action increases rapidly with increases in displacement, depending also on the cladding's connections and on the supporting structure stiffness.

- The force-displacement unloading branches and the respective stiffness and resistance values constitute reasonable estimations of the actual behavior. No cyclic loading or buckling was examined.

- Strain rate effects can efficiently be accounted for with the use of dynamic increase factors, as indicated in [6].

- Close-in or contact explosions that may lead to shear failure and perforation in the cladding are not taken into account. It is assumed that the charge is positioned at sufficient distance from the cladding so that the developing blast pressure is uniformly distributed.

- Blast loading was applied as an equivalent triangular load with the same maximum pressure and positive impulse as the actual exponential blast loading, by altering the blast positive phase duration and neglecting the negative phase effects.

In future extension of the present research, some of these limitations could be overcome by properly accounting for more sophisticated models of the distribution of mass and stiffness, the support reactions, the force-displacement diagram of the cladding, the strain rate effects, and the blast loading. However, the results obtained from the two-step analysis and presented in the following Sections 3 and 4 are considered to be sufficiently accurate despite these limitations, as also confirmed by the numerical results presented in Section 5 .

\section{Influence of Cladding with Both Bending and Membrane Stiffness}

The two-step SDOF analysis can be uniquely described by the five parameters identified in Section 2.1. Appropriate values were assigned to these parameters in order to produce the qualitative and quantitative diagrams shown in the present section. These parameters are further detailed as follows:

- $\quad m_{2} / m_{1}$ : The mass of the supporting structure $\left(m_{2}\right)$ is typically lower than the cladding mass $\left(m_{1}\right)$. Hence, the cases of $m_{2} / m_{1}=0.1$ and $m_{2} / m_{1}=1.0$ are presented. 
- $\quad k_{2} / k_{1,1}$ : The stiffness of the supporting structure $\left(k_{2}\right)$ is significantly larger than the cladding bending stiffness $\left(k_{1,1}\right)$. Hence, the cases of $k_{2} / k_{1,1}=10.0$ and $k_{2} / k_{1,1}=100.0$ are presented.

- $R_{u} / P_{o}$ : The ultimate resistance of the cladding $\left(R_{u}\right)$ may be either larger or lower than the maximum blast pressure $\left(P_{o}\right)$. As a consequence, two extreme values were assigned to this ratio $\left(R_{u} / P_{o}=0.1\right.$ and $\left.R_{u} / P_{o}=2.0\right)$, as well as three intermediate values $\left(R_{u} / P_{o}=0.5,1.0,1.5\right)$.

- $\quad k_{1,3} / k_{1,1}$ : Six cases were examined with regard to the cladding membrane stiffness. These cases are presented in Figure 3 and can be described by only flexural response without plasticity $\left(k_{1,3} / k_{1,1}=1.00,2.00\right)$, flexural and early membrane response $\left(k_{1,3} / k_{1,1}=0.50,0.75\right)$, and flexural and late membrane response $\left(k_{1,3} / k_{1,1}=0.10\right.$, $0.25)$. The discussed ratios are also examined in [13].

- $t_{d} / T_{2}$ : A wide spectrum of $t_{d} / T_{2}$ ratios was investigated in order to efficiently calculate the $D L F_{2}$ at all response types, i.e., at the impulsive regime $\left(t_{d} / T_{2}<0.1\right)$, the dynamic regime $\left(0.1<t_{d} / T_{2}<10.0\right)$, and the quasi-static regime $\left(t_{d} / T_{2}>10.0\right)$ [21]. More specifically, $D L F_{2}$ was calculated at 401 points ranging from $t_{d} / T_{2}=0.01$ to $t_{d} / T_{2}=100.0$. In the same context with the well-known ductility ratio or DLF diagrams used in blast-resistant design [22], the $t_{d} / T_{2}$ ratio was applied in the horizontal axis of the diagrams that are shown in this study.

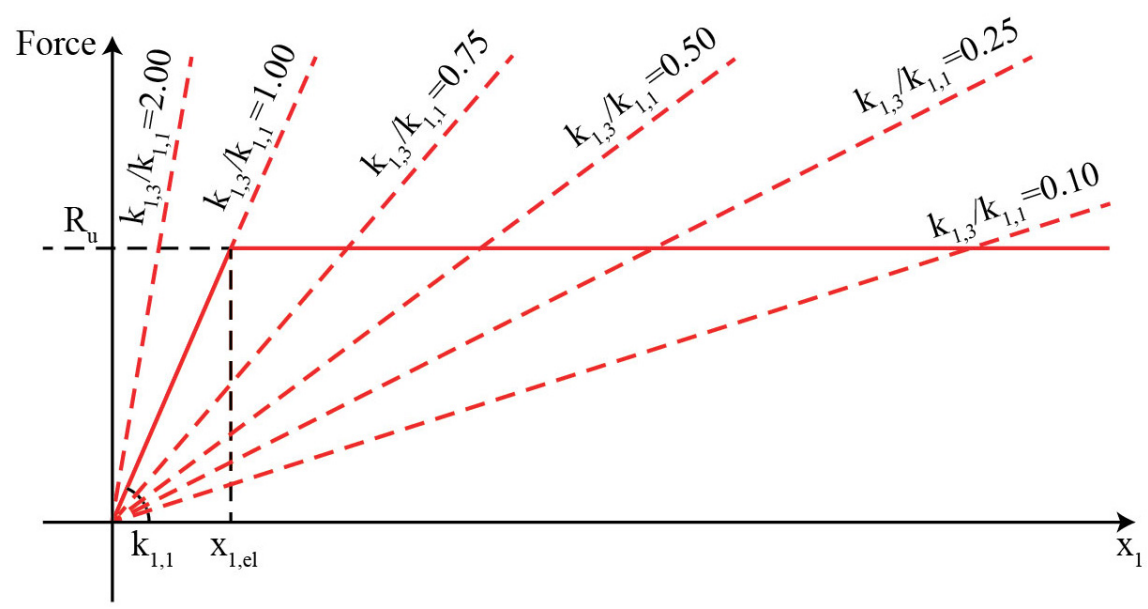

Figure 3. Force-displacement diagram of cladding at multiple membrane stiffness ratios $\left(k_{1,3} / k_{1,1}=\right.$ $0.10,0.25,0.50,0.75,1.00,2.00)$.

It is noted that despite the reasonable selection of specific values in the aforementioned parameters, the observations that are made in the present section about the cladding membrane behavior influence on the supporting structure were also verified at additional values of the parameters. Hence, these observations can be considered to be of general validity for a wide range of cladding-to-supporting structure arrangements.

The diagrams included in Figures 4 and 5 were produced with the aforementioned representative values. More specifically, both figures refer to the same mass and stiffness ratios $\left(m_{2} / m_{1}=0.1,1.0, k_{2} / k_{1,1}=10.0,100.0\right.$, and $\left.k_{1,3} / k_{1,1}=0.1,0.5,1.0\right)$ but different resistance ratios $\left(R_{u} / P_{o}=0.1,1.0,2.0\right.$ in Figure $4, R_{u} / P_{o}=0.5,1.5,2.0$ in Figure 5). The resistance ratio $R_{u} / P_{o}=2.0$ is common between the two figures because it represents the elastic cladding response. Hence, all possible observations should be made by comparing the other curves with the $R_{u} / P_{o}=2.0$ curve (black curve), which is the same for all stiffness ratios. 

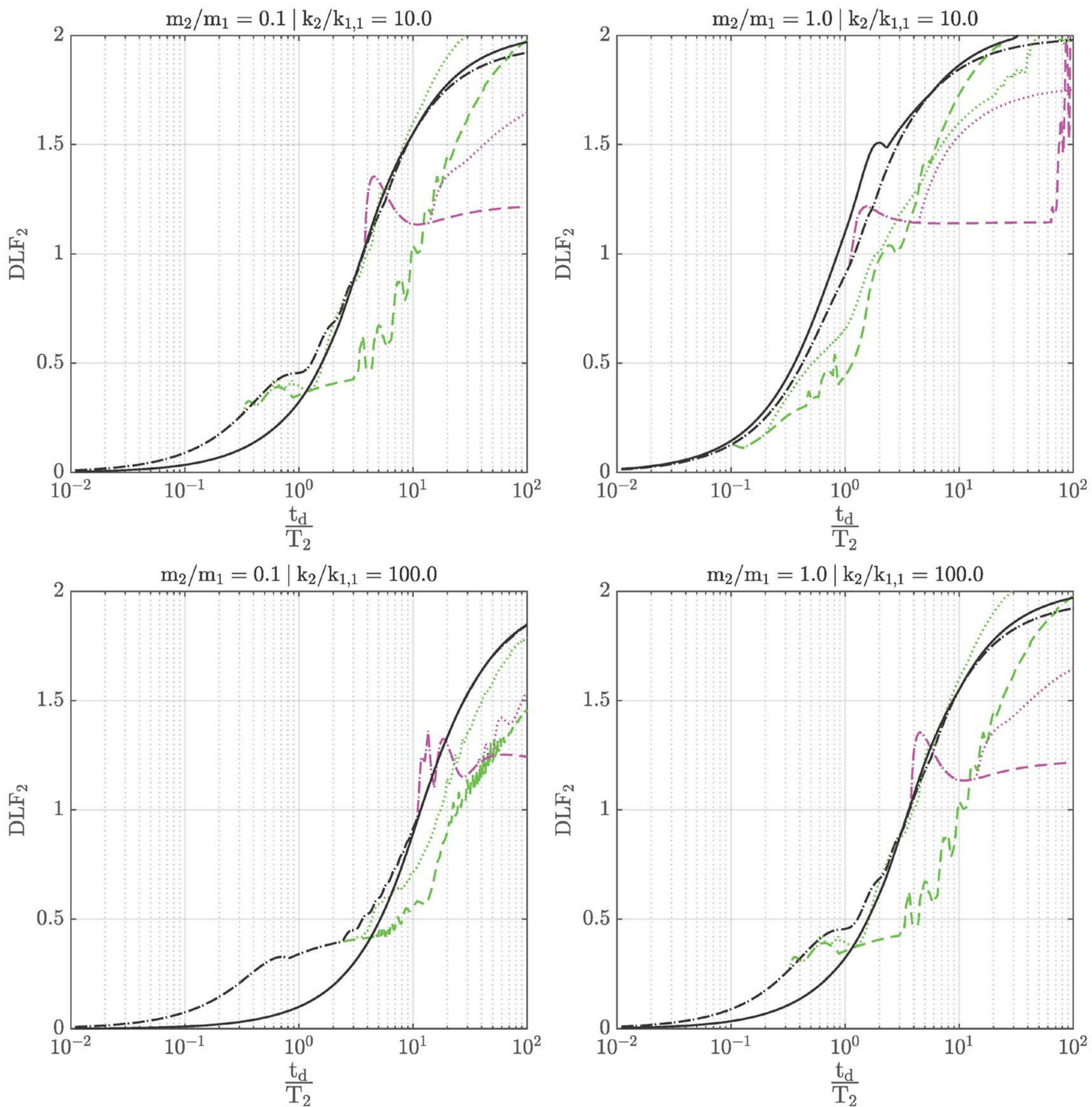

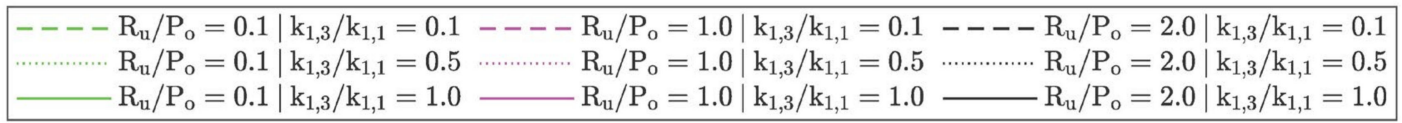

Figure 4. $\mathrm{DLF}_{2}$ of supporting structure for typical mass, bending stiffness, and membrane stiffness arrangements $\left(m_{2} / m_{1}=0.1,1.0, k_{2} / k_{1,1}=10.0,100.0\right.$, and $\left.k_{1,3} / k_{1,1}=0.1,0.5,1.0\right)$ at resistance ratios $R_{u} / P_{o}=0.1,1.0,2.0$.

Similar diagrams are presented in Figure 6 but with fixed values for the mass ratio $m_{2} / m_{1}$ and bending stiffness ratio $k_{2} / k_{1,1}$, as their main purpose is to capture the effect of membrane stiffness ratio $k_{1,3} / k_{1,1}$ in combination with the resistance ratio $R_{u} / P_{o}$. The selected values were representing typical cladding-to-supporting structure arrangements, i.e., $m_{2} / m_{1}=0.1$ and $k_{2} / k_{1,1}=10.0$.

The main contribution of the cladding to the response of the supporting structure is presented in the dynamic and the quasi-static regime. This observation is supported by the fact that the lower the resistance ratio $R_{u} / P_{o}$ is, the lower the positive phase duration to natural period ratio $t_{d} / T_{2}$ is, for which the cladding comes into effect. Hence, the cladding influence could be exhibited in the impulsive regime only for significantly low resistance ratios $R_{u} / P_{o}$, low stiffness ratios $k_{2} / k_{1,1}$ and $k_{1,3} / k_{1,1}$, as well as high mass ratios $m_{2} / m_{1}$.

With regard to the dynamic and the quasi-static regime, the influence of the cladding can be calculated by the reduction in the $D L F_{2}$ curve (in black) at the same positive phase duration to natural period ratio $t_{d} / T_{2}$ as the one of interest. The reduction can have limited or extended magnitude and is strongly dependent upon the various examined parameters. 
Furthermore, the reduction may be present either for only a narrow range or, conversely, for a wide range of $t_{d} / T_{2}$ ratios.
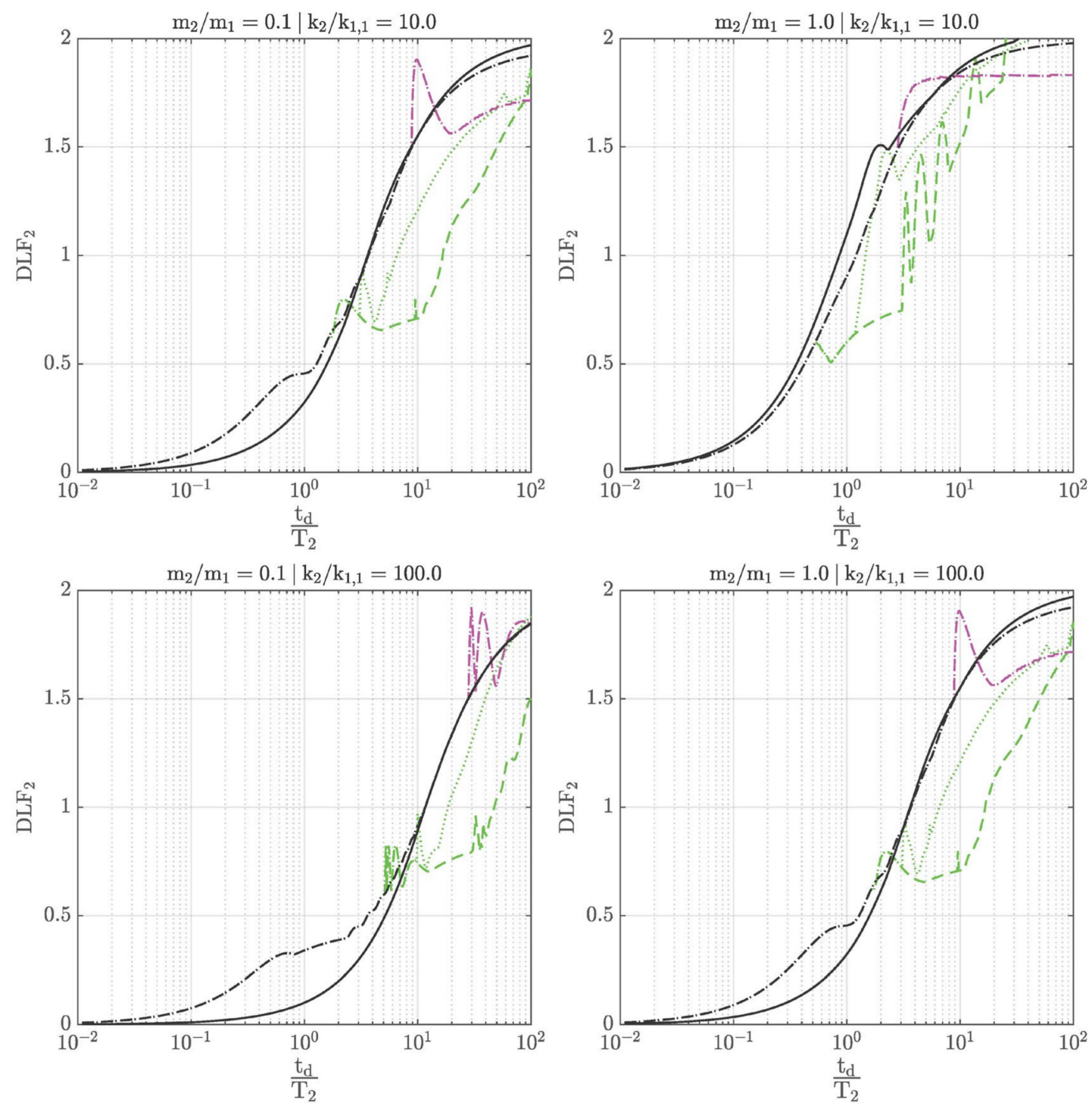

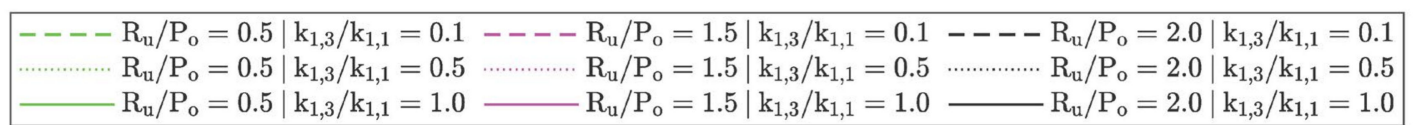

Figure 5. $D L F_{2}$ of supporting structure for typical mass, bending stiffness, and membrane stiffness arrangements $\left(m_{2} / m_{1}=0.1,1.0, k_{2} / k_{1,1}=10.0,100.0\right.$, and $\left.k_{1,3} / k_{1,1}=0.1,0.5,1.0\right)$ at resistance ratios $R_{u} / P_{o}=0.5,1.5,2.0$.

More specifically, the resistance ratio $R_{u} / P_{o}$ seems to have a prevalent role in the response of the supporting structure. When $R_{u} / P_{o}$ is low (i.e., equal to 0.1 or 0.5 ), the effects on $D L F_{2}$ are exhibited early and can be estimated to have an approximately $30 \sim 50 \%$ reduction in the displacement of the supporting structure. However, this is not applicable for all membrane stiffness ratios $k_{1,3} / k_{1,1}$ because, when the membrane action is significant $\left(k_{1,3} / k_{1,1}=0.5,1.0\right)$, plastic dissipation cannot be efficiently activated, and the respective effects on $D L F_{2}$ are minor. Increases in cladding displacements lead to substantial membrane action with simultaneous increase in the corresponding support reactions acting over the supporting structure. Hence $D L F_{2}$ ends up being the same as if blast loading were applied directly to the supporting structure (via the corresponding tributary area), without taking into account the cladding characteristics. 
A similar behavior is observed for large resistance ratios $R_{u} / P_{o}$ but, in this case, the $D L F_{2}$ reduction is applicable for a range of positive phase duration to natural period ratios $t_{d} / T_{2}$ only in the quasi-static regime. Hence, cladding ductility is utilized differently with respect to the supporting structure response regime. Large resistance ratios $R_{u} / P_{o}$ should be used only in the quasi-static regime, while small resistance ratios $R_{u} / P_{o}$ should be used both in the dynamic and the quasi-static regime. However, at all resistance ratios $R_{u} / P_{o}$ the membrane stiffness ratio $k_{1,3} / k_{1,1}$ should be as small as possible in order for plastic energy absorption to take place.
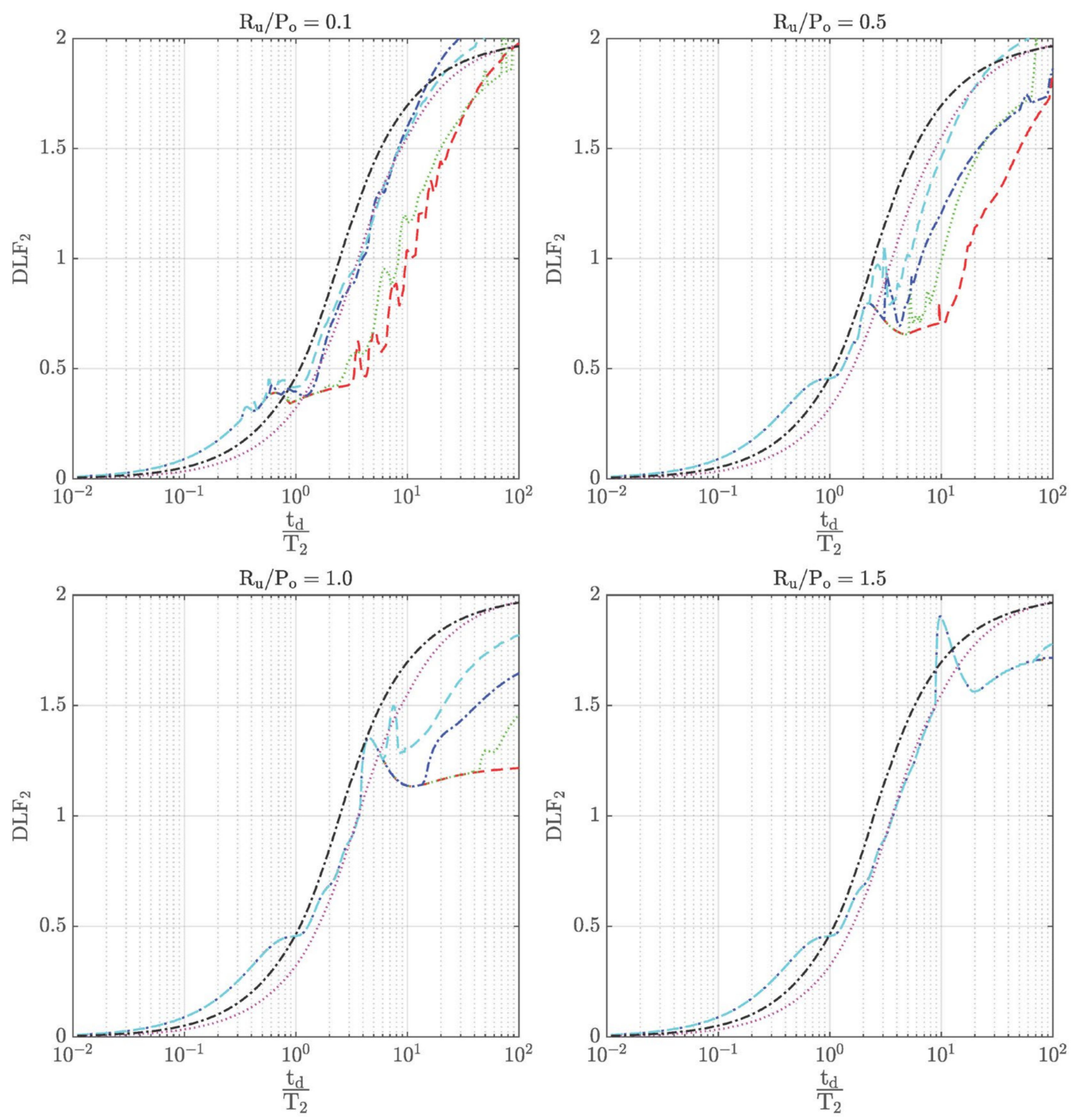

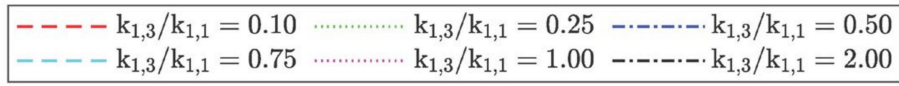

Figure 6. $D L F_{2}$ of supporting structure for mass ratio $m_{2} / m_{1}=0.1$, bending stiffness ratio $k_{2} / k_{1,1}=10.0$, and various membrane stiffness ratios $\left(k_{1,3} / k_{1,1}=0.10,0.25,0.50,0.75,1.00,2.00\right)$ at resistance ratios $R_{u} / P_{o}=0.1,0.5,1.0,1.5$.

The effects of mass and bending stiffness are significant and effective at the whole spectrum of positive phase duration to natural period ratios $t_{d} / T_{2}$. More specifically, it is preferred for mass $m_{1}$ to have large values and bending stiffness $k_{1,1}$ to have small values. In this way, the inertial resistance mechanism of the cladding comes into effect. This mechanism is associated with decreased cladding velocity and, thus, with reduced kinetic energy applied to the cladding [6]. The reduced kinetic energy is critical because it 
is subsequently converted into strain energy and, thus, into reduced displacements for the supporting structure.

\section{Influence of Cladding as a Membrane Structure}

Generally, cladding could be designed with negligible bending stiffness in contrast with its membrane stiffness. Then, cladding can be considered as a membrane structure, without bending stiffness $k_{1,1}$ and resistance $R_{u}$. This case is indicated by parameters $k_{1,3} / k_{1,1}=1.0,2.0$ of Figure 3. Pertinent $D L F_{2}$ results of this type of structure are presented in Figure 7 for multiple mass and stiffness ratios.

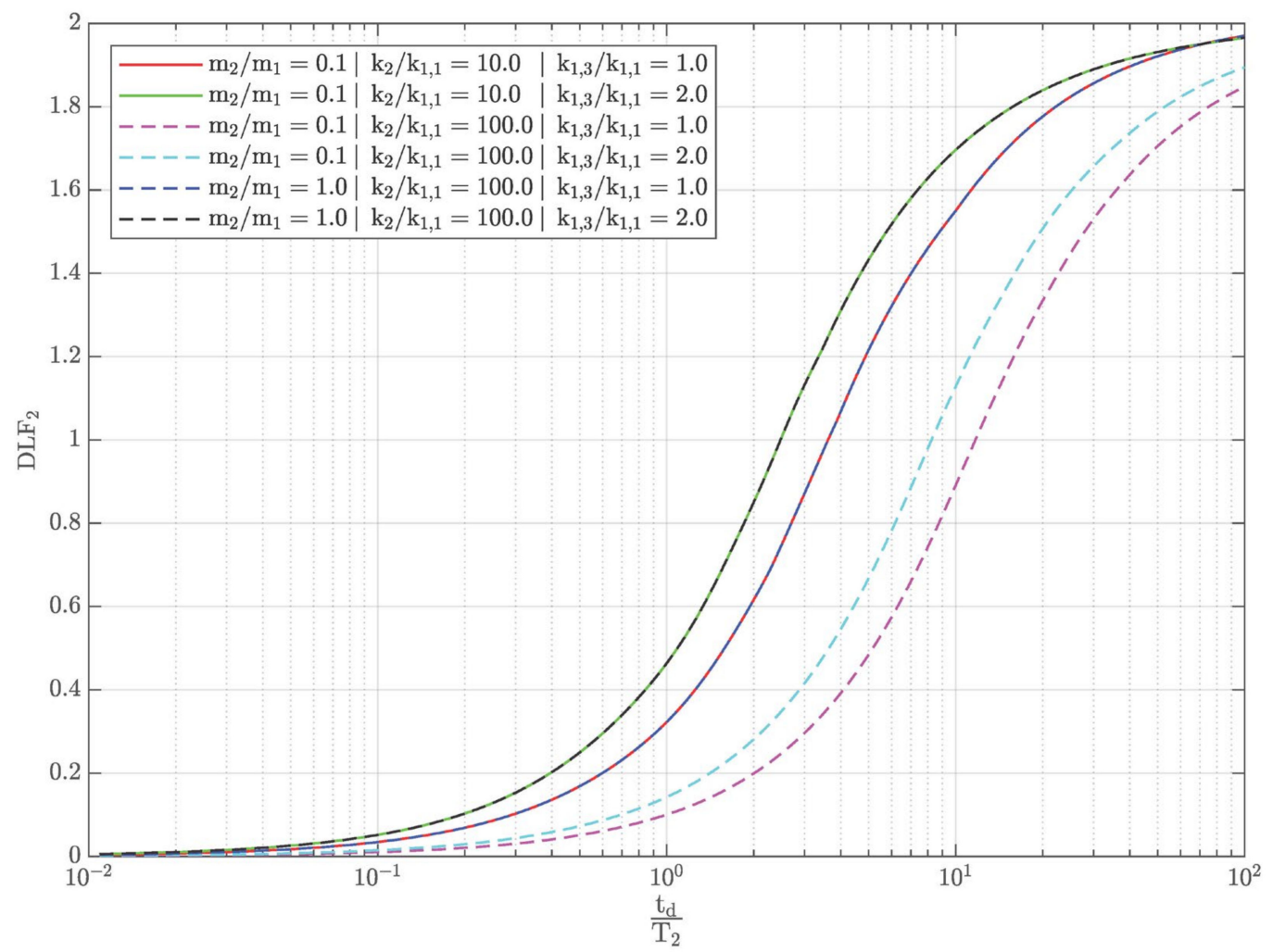

Figure 7. $\mathrm{DLF}_{2}$ of supporting structure when cladding is considered to be a membrane structure with $k_{1,3} / k_{1,1}=1.0,2.0$ at mass ratios $m_{2} / m_{1}=0.1,1.0$ and bending stiffness ratios $k_{2} / k_{1,1}=10.0,100.0$.

As observed, the cladding mass and stiffness exhibit significant influence over the supporting structure. Increases in mass $m_{1}$ and decreases of membrane stiffness $k_{1,3}$ may reduce $D L F_{2}$ by as much as $70 \%$. Furthermore, these effects are active across the whole range of positive phase duration to natural period ratios $t_{d} / T_{2}$, i.e., at the impulsive, dynamic, and quasi-static regime. This fact is of particular interest because the effects of the resistance ratio $R_{u} / P_{o}$ are mainly applicable to the dynamic and the quasi-static regime, while they are also dependent upon the maximum pressure $P_{o}$ for the determination of $R_{u}$ and the proper design of the cladding. Hence, designing the cladding with low membrane stiffness and increased mass could yield substantial effects over the $D L F_{2}$ without the need for the beforehand estimation of maximum blast pressure $P_{o}$.

\section{Case Study}

A case study of a typical cladding-to-column arrangement was selected in order to verify the proposed two-step SDOF analysis and demonstrate the membrane effects of cladding over the supporting structure. A numerical model was prepared in ANSYS Explicit Dynamics software [23], and appropriate NTFE (Nonlinear Transient Finite Element) analyses executions were performed. 
The considered cladding comprised a steel trapezoidal sheet with a height of $100 \mathrm{~mm}$, thickness of $5 \mathrm{~mm}$, crest width of $100 \mathrm{~mm}$, and valley width of $100 \mathrm{~mm}$, as shown in Figure 8. Its geometry was similar to the profiled sheeting that was used in [24], and its static pressure-displacement curve was calculated as indicated in Figure 9. The supporting structure comprised IPE 330 columns that were considered to be pinned-pinned, while the trapezoidal sheeting was assumed to be welded to the columns through the detail presented in Figure 10. The column spacing and length were defined as $4 \mathrm{~m}$ and $2 \mathrm{~m}$, respectively.
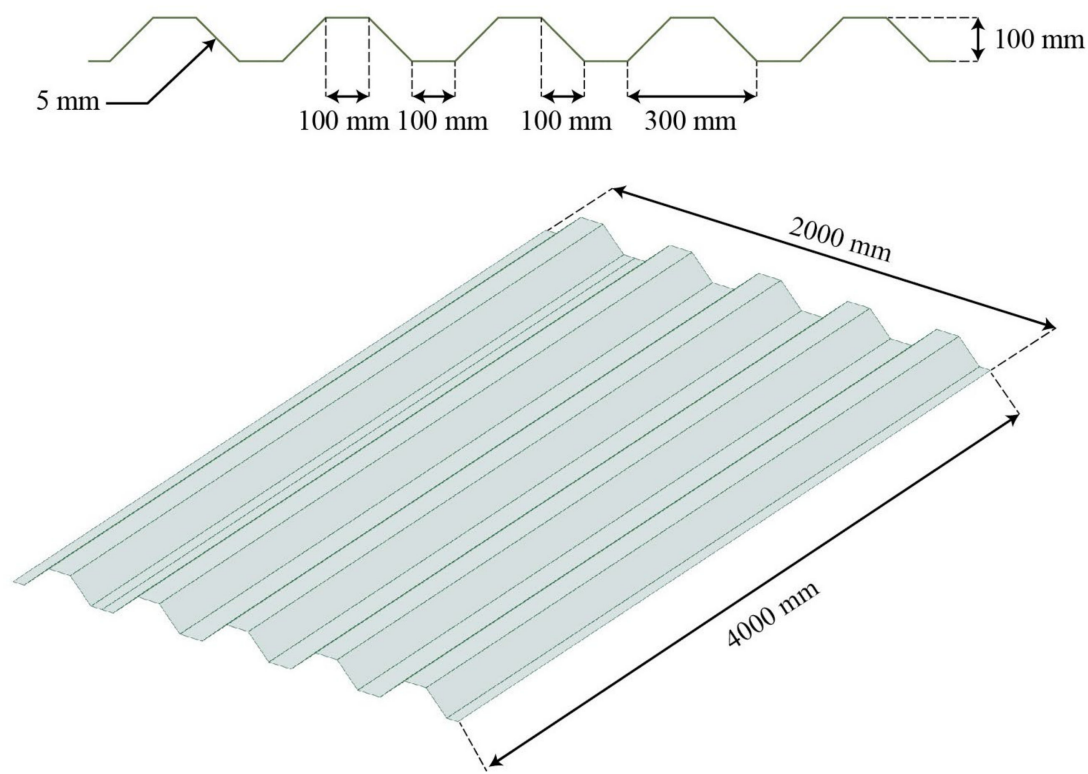

Figure 8. Geometry of the trapezoidal sheet considered in the case study.

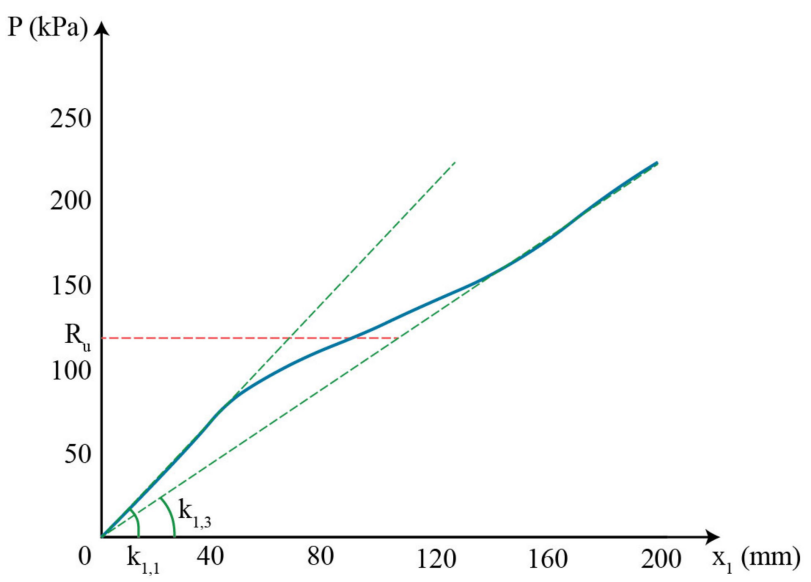

Figure 9. Static pressure-displacement curve (resistance curve) of the trapezoidal sheet considered in the case study. 


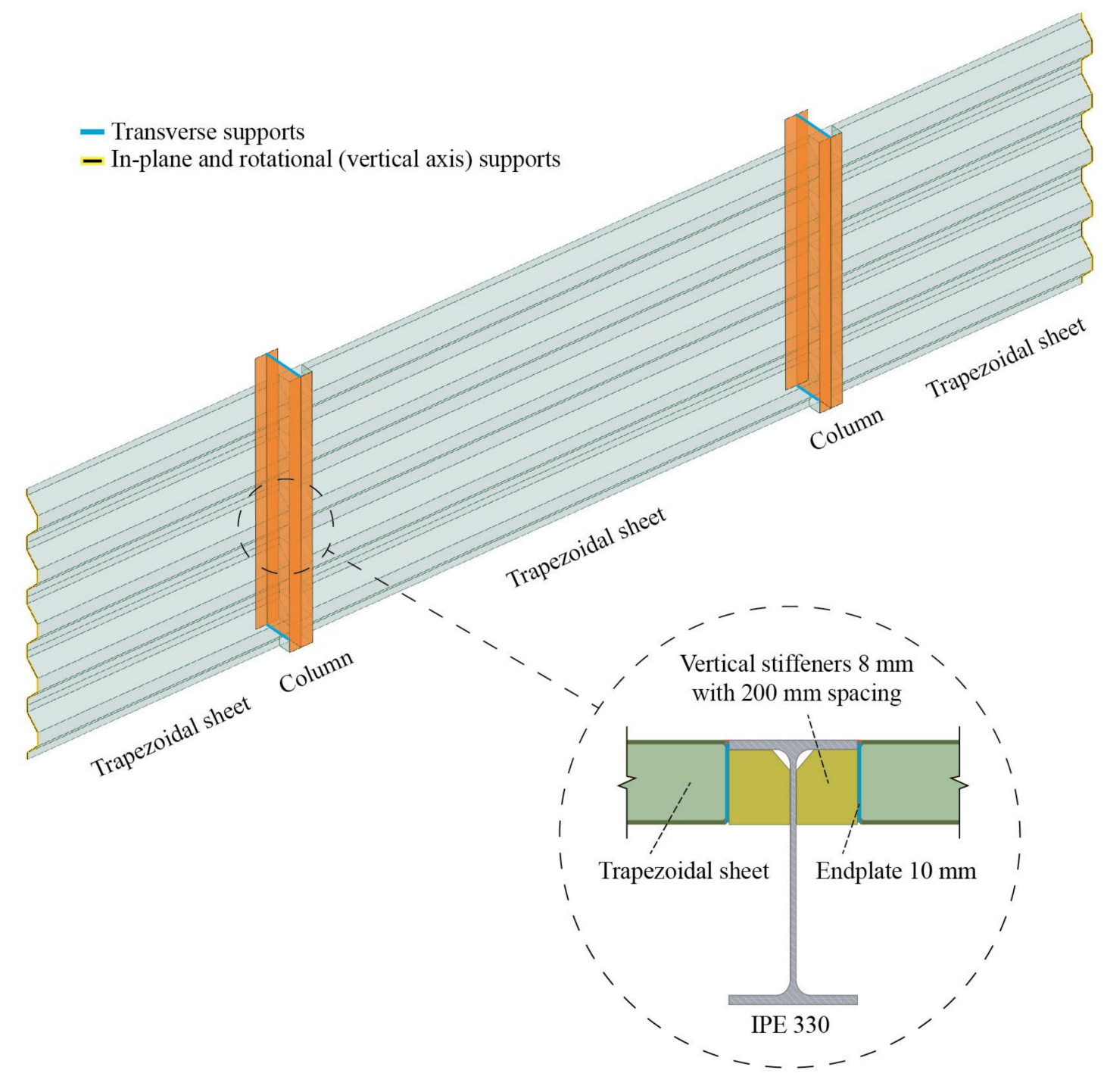

Detail of trapezoidal sheet to IPE 330 connection

Figure 10. 3D view of the cladding-to-column arrangement that was implemented in the case study.

The selected material was steel S355 [25] with a yield strength of $410 \mathrm{MPa}$ [26] due to the static increase factor (representing the difference between the designed steel quality and the actual steel quality). In the numerical model the hardening effects were taken into account by considering the Johnson-Cook model [27], while the strain rate effects were taken into account by considering the Cowper-Symonds model [28]. These models are described by Equation (19), with the relevant values shown in Table 1 for the hardening parameters $(B, \theta)$ and for the strain rate parameters $(D, q)[29,30]$. In Equation (19), plastic stress, yield strength, plastic strain, and plastic strain rate are denoted by $\sigma, A, \varepsilon_{p l}$, and $\dot{\varepsilon}_{p l}$, respectively. These effects were accounted for in the two-step SDOF analysis through the Dynamic Increase Factor (DIF), which was assigned to the resistance $R_{u}$.

$$
\sigma=\left(A+B \cdot \varepsilon_{p l}^{\theta}\right) \cdot\left(1+\left(\frac{\dot{\varepsilon}_{p l}}{D}\right)^{1 / q}\right)
$$

Blast loading was applied as an equivalent triangular pressure, as shown in Figure 1. A pressure amplitude of $200 \mathrm{kPa}$ was applied, as it reflects a typical mid-range blast loading (e.g., $20 \mathrm{~kg}$ at a stand-off distance of $10 \mathrm{~m}$ ), which is considered as appropriate, 
assuming that the panel belongs to a building with perimeter protection (fence and barriers). A variety of maximum blast pressure-impulse combinations was applied to the cladding. All combinations had the same maximum blast pressure but different positive phase duration, as indicated in Figure 11. This pressure control procedure was chosen because each curve that was shown at the relevant $D L F_{2}$ diagrams of the previous paragraphs can be produced by fixed values at all parameters, except for the positive phase duration $t_{d}$, which dictates the ratio $t_{d} / T_{2}$. It is noted that pressure control can be achieved though positive phase duration by increasing impulse, which is the integral of pressure over time.

Table 1. Parameters values of the Johnson-Cook and the Cowper-Symonds models [29,30].

\begin{tabular}{cc}
\hline Parameter & Value \\
\hline$A$ & $410 \mathrm{MPa}$ \\
$B$ & $782 \mathrm{MPa}$ \\
$\theta$ & 0.562 \\
$D$ & 4000 \\
$q$ & 5 \\
\hline
\end{tabular}

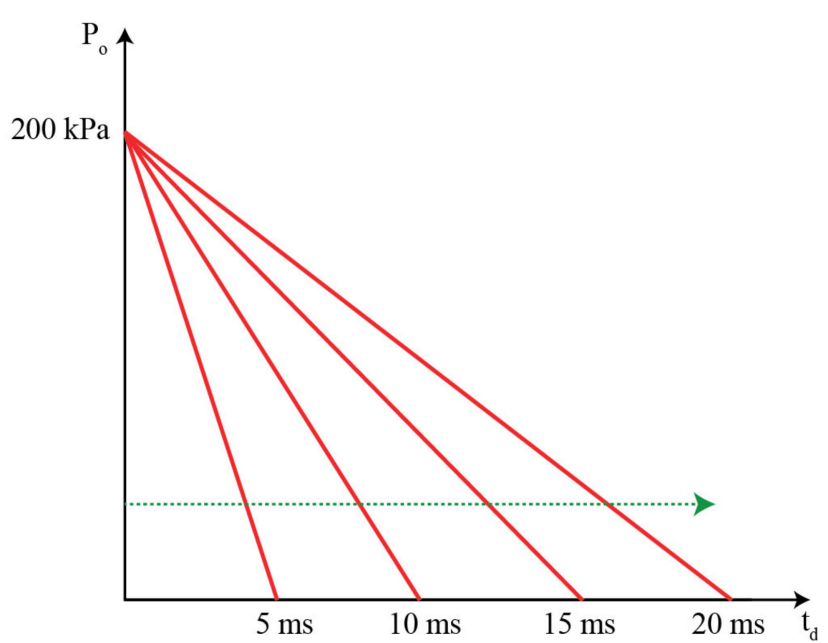

Figure 11. Combinations of maximum blast pressure and positive phase duration (pressurecontrolled scenarios) applied to the cladding of the case study.

The procedure that was used in the two-step SDOF analysis was the same as the one described in paragraph 2. However, along with masses $m_{1}$ and $m_{2}$, proper $K_{L M}$ factors (load-mass transformation factors) [21] were applied in order to convert the structural components into SDOF models with approximately the same displacement time history. The contribution of these factors is shown in Equations (20)-(26), and the respective values are presented in Table 2.

$$
\begin{gathered}
K_{L M 1} \cdot m_{1} \cdot \ddot{x}_{1}+k_{1,1} \cdot x_{1}=P(t), x_{1}<x_{1, e l} \\
V(t)=a_{1,1} \cdot R(t)+b_{1,1} \cdot P(t), x_{1}<x_{1, e l} \\
K_{L M 1} \cdot m_{1} \cdot \ddot{x_{1}}+D I F \cdot R_{u}=P(t), x_{1, e l} \leq x_{1}<x_{1, m e m} \\
V(t)=a_{1,2} \cdot D I F \cdot R_{u}+b_{1,2} \cdot P(t), x_{1, e l} \leq x_{1}<x_{1, m e m} \\
K_{L M 1} \cdot m_{1} \cdot \ddot{x_{1}}+k_{1,3} \cdot x_{1}=P(t), x_{1} \geq x_{1, m e m} \\
V(t)=\left(2 \cdot N_{p} / L\right) \cdot x_{1}, x_{1} \geq x_{1, m e m} \\
K_{L M 2} \cdot m_{2} \cdot \ddot{x}_{2}+k_{2} \cdot x_{2}=2 \cdot V(t)
\end{gathered}
$$


Table 2. Parameters of the two-step SDOF analysis.

\begin{tabular}{ccc}
\hline Parameter & Value & Source \\
\hline$k_{1,1}$ & $13,251 \mathrm{~N} / \mathrm{mm}$ & Figure 9 \\
$R_{u}$ & $944,001 \mathrm{~N}$ & Figure 9 \\
$k_{1,3}$ & $8883 \mathrm{~N} / \mathrm{mm}$ & Figure 9 \\
$m_{1}$ & $410,000 \mathrm{~g}$ & Manual calculation \\
$K_{L M 1}$ & 0.72 & Average value of fixed-fixed component \\
$I_{y y}$ & $11,770 \mathrm{~cm}^{3}$ & subjected to distributed loading \\
$k_{2}$ & $237,283 \mathrm{~N} / \mathrm{mm}$ & Manual calculation \\
$m_{2}$ & $31,400 \mathrm{~g}$ & $\left(384 \cdot E \cdot I_{y y}\right) /\left(5 \cdot \mathrm{L}^{3}\right)$ \\
$K_{L M 2}$ & 0.78 & Manual calculation \\
$D I F$ & 1.20 & Elastic bending of pinned-pinned component \\
$N_{p} / \mathrm{L}$ & $2221 \mathrm{~N} / \mathrm{mm}$ & subjected to distributed loading \\
$x_{1, e l}$ & $85.5 \mathrm{~mm}$ & {$[21]$} \\
$x_{1, \text { mem }}$ & $127.5 \mathrm{~mm}$ & $k_{1,3} / 4$ [13] \\
\hline
\end{tabular}

The numerical model was created with shell elements of sufficiently dense mesh $(20 \mathrm{~mm})$, as indicated in Figure 12. It was confirmed that the mesh was sufficient through parametric analyses with denser mesh, which exhibited approximately the same results. The duration of the analyses was large enough to capture the maximum displacement and plastic strains of both the cladding and the columns, while the timestep was small enough to satisfy the Courant criterion [23]. As a whole, twenty analyses were performed with each one having a different blast loading defined by an increasing positive phase duration from $1 \mathrm{~ms}$ to $20 \mathrm{~ms}$ with $1 \mathrm{~ms}$ step.

The analysis with the $15 \mathrm{~ms}$ positive phase duration was selected as an example in order to display both the numerical model and the two-step analysis results. This positive phase duration was selected because it was large enough for the cladding to enter into the membrane branch of its resistance curve. The numerical model results are presented in Figure 12, while the comparison with the two-step SDOF analysis is presented in Figure 13.

The displacements and plastic strains of the numerical model are displayed at the instances of $10.0 \mathrm{~ms}$ and $12.7 \mathrm{~ms}$, where the maximum displacement of the column and the cladding are exhibited, respectively. As shown, cladding maximum displacement was extended beyond $x_{1, m e m}$; thus, membrane action of the cladding was initiated. Furthermore, significant plastic strains were observed at the ends and the middle of the cladding, while the columns remained elastic.

Regarding the comparison with the two-step SDOF analysis, the results were verified through the numerical model. The maximum displacements of both the cladding and columns as well as the time of maximum displacement were similar between the two approaches.

Furthermore, useful observations were made through the pressure control procedure, which was applied to the numerical model in order to check the response of the columns by constantly increasing impulse. As presented in Figure 14, for small positive phase durations $t_{d}$, column maximum displacement is linearly increased. Within the range of 4 $\mathrm{ms}$ to $8 \mathrm{~ms}$ the column displacement is approximately constant, while beyond $8 \mathrm{~ms}$ it is further increased until $18 \mathrm{~ms}$. When the positive phase duration is over $18 \mathrm{~ms}$, the column enters into plasticity, and its displacements are rapidly increasing. 

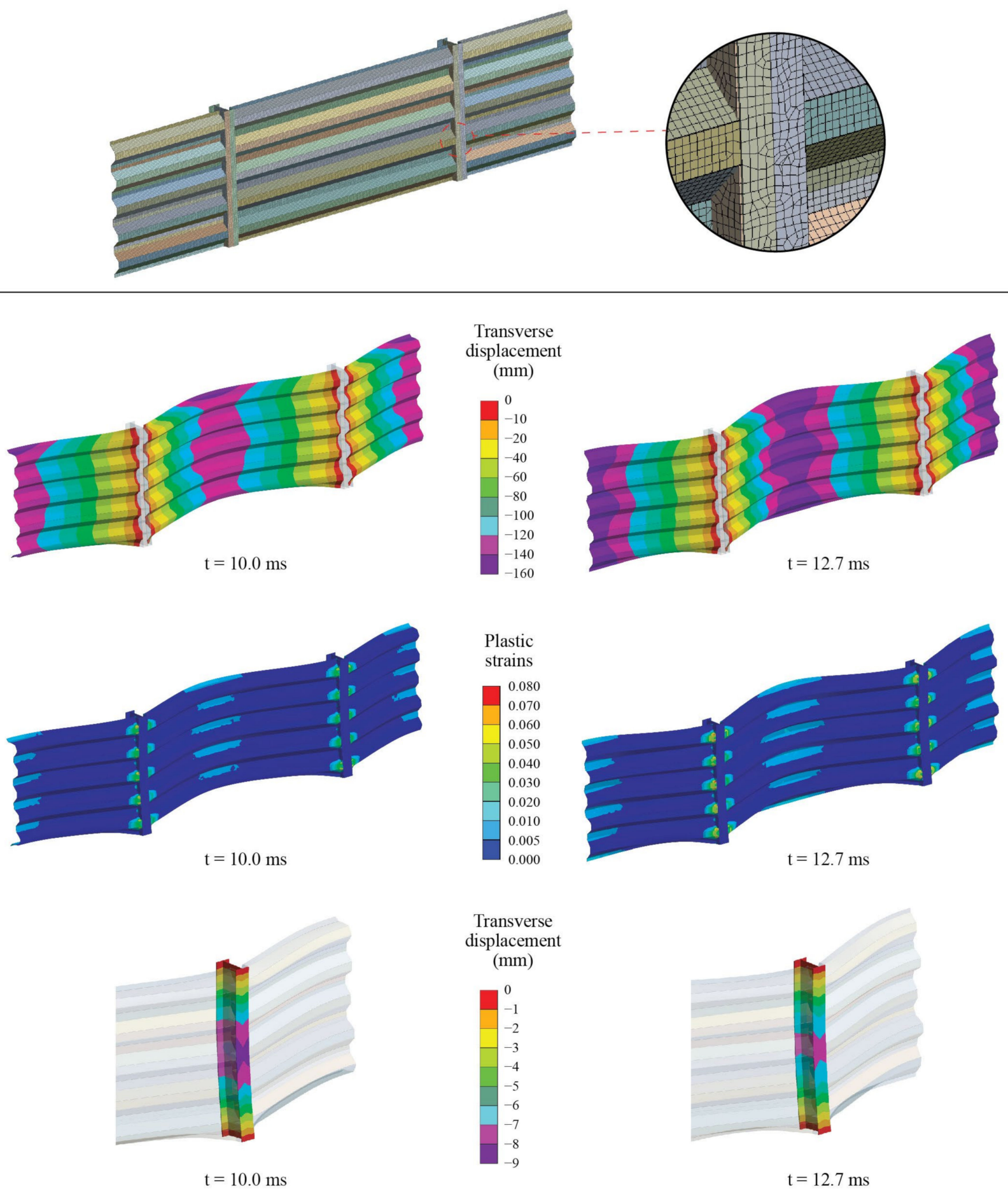

Figure 12. Meshing and results of the case study numerical model when cladding is subjected to $200 \mathrm{kPa}$ maximum blast pressure and $1500 \mathrm{kPa}$ ms impulse (15 ms positive phase duration).

The negative effects of the cladding membrane action are exhibited through the fact that it constitutes an obstacle to plastic energy dissipation. More specifically, bendinginduced plastic strains are beneficial to the supporting structure. However, plastic strains caused by membrane action result in larger support reactions, thus leading to significant increase in the supporting structure displacements. When the cladding's response exceeds $x_{1, m e m}$, the upper limit of resistance $R_{u}$ for the support reactions stops being applicable. 

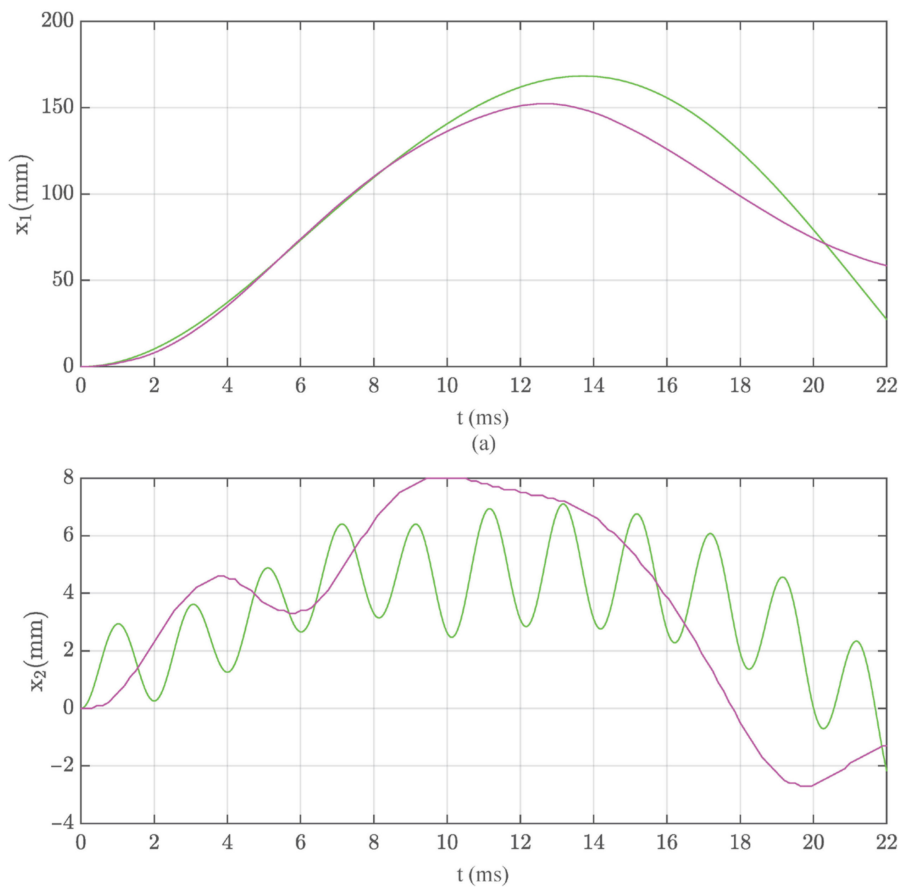

(b)

SDOF results $\longrightarrow$ Numerical model results

Figure 13. Two-step SDOF analysis and numerical model results of the case study (a) cladding and (b) columns when subjected to maximum blast pressure of $200 \mathrm{kPa}$ and positive phase duration of $15 \mathrm{~ms}$.

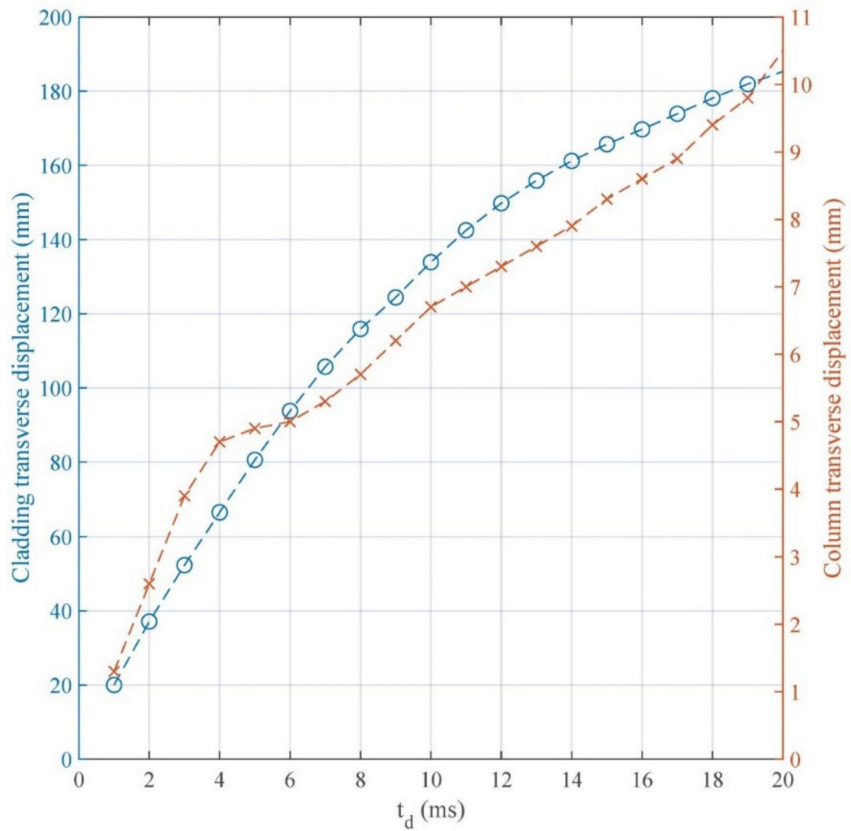

Figure 14. Numerical model transverse displacement of the case study cladding and column at constantly increasing positive phase duration (pressure control).

\section{Conclusions}

The effects of cladding membrane behavior on the supporting structure were explored, focusing on two cases of cladding response. The first case referred to the response of cladding with both bending and membrane stiffness, while in the second case, flexible cladding with only membrane stiffness was considered. The results of the investigation were considered in non-dimensional form so that they would be applicable to multiple 
cladding-to-supporting structure configurations. The observations were concentrated on the fundamental parameters of the cladding, i.e., the cladding mass $m_{1}$, resistance $R_{u}$, bending stiffness $k_{1,1}$, and membrane stiffness $k_{1,3}$.

It was shown that increased membrane stiffness $k_{1,3}$ leads to the enlargement of the support reactions, thus escalating the displacement of the supporting structure. Moreover, when cladding membrane action is initiated, the beneficial effects of cladding plasticity are countered by the contribution of the axial forces to the support reactions. On the contrary, if membrane stiffness is limited, an upper limit is observed in the support reactions, depending on resistance $R_{u}$. Hence, it is preferential that energy absorption is activated though bending behavior instead of membrane behavior.

In addition, when resistance has a low value with regard to maximum blast pressure $P_{o}$, the effects of plasticity are observed both in the dynamic and the quasi-static regime, but they are not constant, as they are limited when positive phase duration $t_{d}$ is increased. However, when resistance has a high value, the effects of plasticity are observed only in the quasi-static regime.

In contradiction to this fact, the effects of mass $m_{1}$ and bending stiffness $k_{1,1}$ are applicable to the whole spectrum of positive phase durations $t_{d}$ and natural periods $T_{2}$, regardless of the impulsive, the dynamic, and the quasi-static regime. More specifically, the supporting structure displacements are limited through increased mass and low bending stiffness in the cladding. In this case, the cladding responds slowly to blast loading, thus yielding low support reactions to the supporting structure. Furthermore, the effects of cladding mass and bending stiffness are applicable to all pressure-impulse combinations, while the effects of resistance depend on the characteristics of blast loading.

As a whole, the observations of the present article are critical for the design of cladding subjected to blast loading. It has been shown that membrane behavior results in adverse consequences for the supporting structure, as it yields unconservative reaction forces, and it should not be neglected during the design procedure. Moreover, membrane behavior should only be activated as a reserve, in order to protect cladding from failure. This is of particular interest for a building façade, where displacements and P- $\Delta$ effects at the main lateral resisting system should be limited.

Author Contributions: Conceptualization, methodology, validation, formal analysis, investigation, resources and data curation, O.I. and C.J.G.; software, writing-original draft preparation, visualization and funding acquisition, O.I.; writing-review and editing, supervision and project administration, C.J.G. All authors have read and agreed to the published version of the manuscript.

Funding: This research was co-financed by Greece and the European Union (European Social FundESF) through the Operational Programme 'Human Resources Development, Education and Lifelong Learning' in the context of the project 'Strengthening Human Resources Research Potential via Doctorate Research' (MIS-5000432), implemented by the State Scholarships Foundation (IK $\Upsilon$ ).

Data Availability Statement: The data are not publicly available due to privacy reasons.

Conflicts of Interest: The authors declare no conflict of interest.

\section{Nomenclature}

$\begin{array}{ll}A & \text { Yield stress } \\ B & \text { Strain hardening coefficient } \\ D & \text { Strain rate effect coefficient } \\ D L F_{\mathrm{i}} & \text { Dynamic load factor of the } i \text { th degree of freedom } \\ D I F & \text { Dynamic increase factor } \\ E & \text { Modulus of elasticity } \\ I_{y y} & \text { Moment of inertia } \\ K_{L M i} & \text { Load mass transformation factor of the } i \text { th degree of freedom } \\ L & \text { Length of component } \\ N_{p} & \text { Axial resistance }\end{array}$




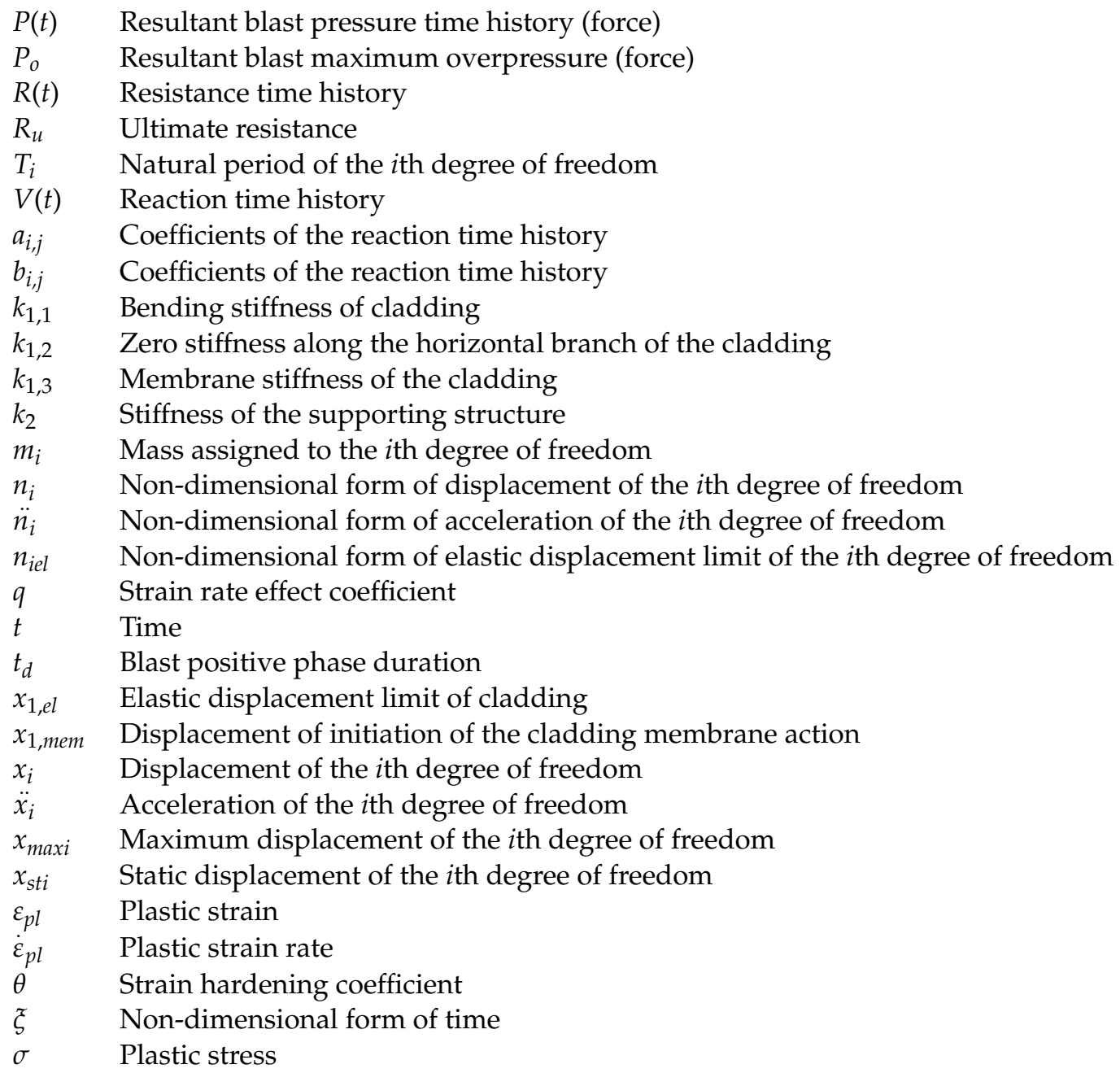

\section{References}

1. Hanssen, A.G.; Enstock, L.; Langseth, M. Close-range blast loading of aluminium foam panels. Int. J. Impact Eng. 2002, 27, 593-618. [CrossRef]

2. Guruprasad, S.; Mukherjee, A. Layered sacrificial claddings under blast loading Part I—Analytical studies. Int. J. Impact Eng. 2000, 24, 957-973. [CrossRef]

3. U.S. Department of Defence. UFC 03-340-02: Structures to Resist the Effects of Accidental Explosions; U.S. Department of Defence: Washington, DC, USA, 2008. Available online: https://www.wbdg.org/ffc/dod/unified-facilities-criteria-ufc/ufc-3-340-02 (accessed on 3 October 2021).

4. Dharmasena, K.P.; Wadley, H.N.G.; Xue, Z.; Hutchinson, J.W. Mechanical response of metallic honeycomb sandwich panel structures to high-intensity dynamic loading. Int. J. Impact Eng. 2008, 35, 1063-1074. [CrossRef]

5. Dharmasena, K.P.; Wadley, H.N.G.; Williams, K.; Xue, Z.; Hutchinson, J.W. Response of metallic pyramidal lattice core sandwich panels to high intensity impulsive loading in air. Int. J. Impact Eng. 2011, 38, 275-289. [CrossRef]

6. Dusenberry, D.O. Handbook for Blast Resistant Design of Buildings; John Wiley \& Sons: Hoboken, NJ, USA, 2010.

7. Hadjioannou, M.; Donahue, S.; Williamson, E.B.; Engelhardt, M.D. Large-scale experimental tests of composite steel floor systems subjected to column loss scenarios. J. Struct. Eng. 2018, 144, 04017184. [CrossRef]

8. Zhang, X.; Hao, H. The response of glass window systems to blast loadings: An overview. Int. J. Prot. Struct. 2016, 7, 123-154. [CrossRef]

9. Pan, Y.; Watson, A. Effect of panel stiffness on resistance of cladding panels to blast loading. J. Eng. Mech. 1998, 124, 414-421. [CrossRef]

10. Del Linz, P.; Hooper, P.A.; Arora, H.; Smith, D.; Pascoe, L.; Cormie, D.; Blackman, B.R.K.; Dear, J.P. Reaction forces of laminated glass windows subject to blast loads. Compos. Struct. 2015, 131, 193-206. [CrossRef]

11. Hoffmeister, B.; Schillo, N.; Colomer, C.; Elghazouli, A.; Nardini, L.; Salvatore, W.; Lecompte, D.; Reymen, B.; Vantomme, J.; Maljaars, J.; et al. Advanced design methods for blast Loaded steel structures. Eur. Comm. Dir. Res. Innov. 2015. [CrossRef] 
12. Fire and Blast Information Group. Technical Note 7: Simplified Methods for Analysis of Response to Dynamic Loading; Fire and Blast Information Group: Berkshire, UK, 2002. Available online: https://www.fabig.com/publications-and-videos/technicalguidance/technical-note-07/ (accessed on 3 October 2021).

13. The Norwegian Oil Industry Association. NORSOK N-004: Design of Steel Structures; The Norwegian Oil Industry Association: Lysaker, Norway, 2004. Available online: https:/ / www.standard.no/pagefiles/1145/n-004.pdf (accessed on 3 October 2021).

14. Health and Safety Executive. Design, Materials and Connections for Blast-Loaded Structures; Health and Safety Executive: Warrington, UK, 2006. Available online: https:/ / www.hse.gov.uk/research/rrpdf/rr405.pdf (accessed on 3 October 2021).

15. Biggs, J.M. Introduction to Structural Dynamics; McGraw-Hill: New York, NY, USA, 1964.

16. Gantes, C.J.; Pnevmatikos, N.G. Elastic-Plastic Response Spectra for Exponential Blast Loading. Int. J. Impact Eng. 2004, 30, 323-343. [CrossRef]

17. Rigby, S.E.; Tyas, A.; Bennett, T. Single-Degree-of-Freedom response of finite targets subjected to blast loading-The influence of clearing. Eng. Struct. 2012, 45, 396-404. [CrossRef]

18. Krauthammer, T.; Altenberg, A. Negative phase blast effects on glass panels. Int. J. Impact Eng. 2000, 24, 1-17. [CrossRef]

19. The MathWorks Inc. MATLAB (R2018a); The MathWorks Inc.: Natick, MA, USA, 2018.

20. U.S. Army Corps of Engineers. PDC TR-06-01: Single Degree of Freedom Blast Design Spreadsheet (SBEDS) Methodology Manual; U.S. Army Corps of Engineers: Washington, DC, USA, 2006. Available online: https:/ / www.nwo.usace.army.mil/About/Centers-ofExpertise/Protective-Design-Center/PDC-Library/ (accessed on 3 October 2021).

21. Cormie, D.; Mays, G.; Smith, P. Blast Effects on Buildings; ICE Publishing: London, UK, 2009.

22. U.S. Army Corps of Engineers. TM5-856-3: Design of Structures to Resist the Effects of Atomic Weapons; U.S. Army Corps of Engineer: Washington, DC, USA, 1957. Available online: https://usace.contentdm.oclc.org/digital/collection/p16021coll9/id/1714/ (accessed on 3 October 2021).

23. ANSYS Inc. ANSYS Explicit Dynamics (18.1); Technology Drive: Canonsburg, PA, USA, 2017.

24. Health and Safety Executive. Analysis and Design of Profiled Blast Walls; Health and Safety Executive: London, UK, 2004. Available online: https: / /www.hse.gov.uk/research/rrpdf/rr146.pdf (accessed on 3 October 2021).

25. British Standards Institution. BS EN 10025-2:2019: Hot Rolled Products of Structural Steels; Europe, 2019. Available online: https:/ / shop.bsigroup.com/products/hot-rolled-products-of-structural-steels-technical-delivery-conditions-for-non-alloystructural-steels-1 (accessed on 3 October 2021).

26. Braconi, A.; Caprili, S.; Degee, H.; Guendel, M.; Hjiaj, M.; Hoffmeister, B.; Karamanos, S.A.; Rinaldi, V.; Salvatore, W.; Somja, H. Efficiency of Eurocode 8 design rules for steel and steel-concrete composite structures. J. Constr. Steel Res. 2015, 112, 108-129. [CrossRef]

27. Johnson, G.R.; Cook, W.H. A constitutive model and data from metals subjected to large strains, high strain rates and high temperatures. In Proceedings of the Seventh International Symposium on Ballistics, Hague, The Netherlands, 19-21 April 1983.

28. Cowper, G.; Symonds, P. Strain hardening and strain-rate effects in the impact loading of cantilever beam. Brown Univ. Div. Appl. Math. 1957. [CrossRef]

29. Cadoni, E.; Forni, D.; Gieleta, R.; Kruszka, L. Tensile and compressive behaviour of S355 mild steel in a wide range of strain rates. Eur. Phys. J. Spec. Top. 2018, 227, 29-43. [CrossRef]

30. Mortazavi, M.; Heo, Y.A. Nonlinear dynamic response of steel materials and plain plate systems to impact loads: Review and validation. Eng. Struct. 2018, 173, 758-767. [CrossRef] 